\title{
FEMA P695 methodology for safety margin evaluation of steel moment resisting frames subjected to near-field and far-field records
}

\author{
Mahdi Heshmati ${ }^{1} \cdot$ Alireza Khatami $^{1}$ (D) $\cdot$ Hamzeh Shakib ${ }^{1}$
}

Received: 25 August 2020 / Accepted: 15 January 2021 / Published online: 23 January 2021

(C) The Author(s) 2021 OPEN

\begin{abstract}
This study presents the impact of near-field and far-field earthquakes on the seismic design of Intermediate Moment Resisting Frame (IMRF) and Special Moment Resisting Frame (SMRF) structures through FEMA (Federal Emergency Management Agency) P695 methodology to highlight the importance of probabilistic collapse as well as seismic performance factors of these structures. The purpose of this study is to investigate the collapse performance of steel intermediate and special moment resisting frame systems as the most common structural systems in urban areas in order to assess the seismic performance factors used for the design using nonlinear static and dynamic analysis methods. In this regard, as the representatives of low-rise to high-rise buildings, archetypes with 5-, 10- and 15- story of intermediate and special moment resisting frames are designed and then the nonlinear models are developed in OpenSees software. Nonlinear static analyses are performed to assess the overstrength and ductility of these systems. The effects of near-field and far-field ground motions on these frames are investigated through incremental dynamic analysis. These analyses are performed with 22 far-field and 20 near-field ground motion records using FEMA P695 methodology. The results show that near-field earthquakes have serious impacts on the collapse probability of structures. The superiority of special moment resisting frame over intermediate moment resisting frame is quantified in terms of safety margin and median collapse capacity under both near-field and far-field earthquakes. Finally, the results indicate that the response modification factors introduced in seismic design code are acceptable for intermediate moment resisting frame and special moment resisting frame under far-field ground motions. However, in the near-field sites while SMRF system meets the requirements of FEMA P695 methodology, the IMRF system does not satisfy these criteria.
\end{abstract}

Keywords MRF · Pushover · Incremental dynamic analysis (IDA) · Near-field and far-field records · Collapse margin ratio (CMR) - Seismic performance factors (SPFs)

\section{Introduction}

Given that natural disasters such as earthquakes cause huge financial or life losses to societies every year, hence, understanding the essence of earthquakes and the effects of various factors on the behavior of structures has made researchers to create different methods in the analysis and design of structures. The results of these studies have been used in preparation of rules and regulations for constructions that have become more inclusive and comprehensive over the time. Although the effects of near-field earthquakes have been known to some extent in the past, the importance of this issue in the design of structures was not well understood until devastating earthquakes such as Landers, Northridge, Kobe and Chi-Chi occurred. Observation of severe and different damages compared to expected deformations gave rise to pay attention to the factors which caused a great deal of damage as opposed

Alireza Khatami, Khatami.alireza.70@gmail.com | 'Department of Civil and Environmental Engineering, Tarbiat Modares University, Tehran, Iran. 
to the predicted behavior of structures. Near-field ground motion records have high frequency content and pulse effects which influence the response of high frequency structures (stiff structures) as well as long period structures (flexible structures). Therefore, considering the effects of site's proximity to seismic sources is an important issue in the seismic design of resistant structures and probabilistic evaluation of buildings should be addressed properly especially under near-field ground motions.

As mentioned above, a new movement has been initiated to study and compare the behavior of steel moment resisting frames subjected to near-field and far-field ground motion records. Alavi and Krawinkler [1] characterized the behavior of structures under near-field earthquakes. A set of parameters were defined to estimate the base shear demand and reflect the properties of near-field ground motions. It was observed that the strength and ductility demands for a wide range of periods are much greater than those presented in design codes. Thus, they tried to develop new equations to estimate the required strength for target ductility. Lee et al. [2] found no logical reasons for calculation of proposed $R$-factor in seismic design codes. Therefore, they tested moment resisting frames with different heights for examining the $R$-factors variations using maximum considered earthquakes. Their results indicated that the designed structures with $R=8.0$ provided a conservative design for low- to mid-rise buildings for collapse prevention performance target. However, tall buildings demonstrated a low degree of confidence in the referred performance objective. Asgarian et al. [3] studied the seismic behavior of moment resisting frames including special moment resisting frames (SMRF), Intermediate moment resisting frames (IMRF) and ordinary moment resisting frame (OMRF) using fragility curves to assess the capability of each system to provide a specific target. In this study, while SMRF system provide a high level of safety in both collapse prevention and immediate occupancy, OMF system exhibited a fairly low confidence under the same hazard level for collapse prevention target. This was mainly attributed to the weak behavior of beam-to-column connections and panel zones. Furthermore, although low-rise IMRF system behaved strongly under strong earthquakes, tall building cases tend to show poorer performance in zones with high seismicity. Asgarian et al. [4] studied different intensity measures (IM) which provided a better estimation of overall structural behavior when the structures are subjected to near-field ground motions. It was indicated that the spectral acceleration at the nth effective-mode period is the most suitable intensity indices for reflecting the pulse like effects of near-field ground motions. Izadnia et al. [5] employed different methods of conventional and adaptive pushover analyses including force based adaptive pushover analysis and displacement based adaptive pushover analysis to derive seismic performance factors. It was concluded that adaptive pushover analyses led to higher seismic demand and increased the response modification factor and ductility factor almost similarly. Kazantzi et al. [6] evaluated the effects of model uncertainties in three construction quality levels on the seismic responses of structures using incremental dynamic analysis and Monte Carlo simulation. The comparison of results revealed that uncertainties had no impacts on the outcomes provided that the global response of the structure is of interest regardless of construction quality. However, it was shown that uncertainties can much more affect the local damages especially in low construction quality. This effect is much more highlighted in structural systems where the strength capacity of components play a major role in resisting against lateral loads. Asgarian and Ordoubadi [7] investigated the influences of structural variables in numerical modeling on the seismic behavior of steel moment resisting frames. They concluded that the uncertainties in numerical modeling resulted in reduced dispersions compared to previous studies. In addition, it was observed that there is a safe gap between performance targets in special moment resisting frames. A new framework for development of fragility functions for steel moment-resisting frames was proposed by Noh et al. [8]. In this framework an indicator of state of structures based on a wavelet-based damage sensitive feature which has been used in structural health monitoring was implemented to estimate the response of structures. This method was shown to have a more reliable with less variance of damage prediction of buildings compared to fragility curves derived from acceleration-based measurements. Otsuki et al. [9] examined the damage characteristics and safety margin of expansion joints between two frames through shaking table tests and 7 displacementdependent damage mechanisms were observed. Finally, repair information including cost for high-performance and standard-performance expansion joints were presented. Macedo et al. [10] studied a more rational method for estimation of behavior factors of moment resisting frames designed based on European seismic design provision. This procedure included the actual properties of the structure and site of the buildings. Based on real response of structures, it was shown that force-based design allows to achieve more material savings. In addition, prediction of ductility demand distribution was better explored. Piluso et al. [11] developed a new methodology for design of MRFs based on prospective considered performance related to collapse probability. Since the aleatoric uncertainty of the material properties was considered in the analyses, the Theory of Plastic Mechanism Control was developed for probabilistic cases rather than deterministic ones already applied in the literature. Kiakojouri et al. 
[12] investigated the collapse behavior of moment resisting frames using static- and dynamic incremental analyses. There important parameters including location of column removal, duration of column removal and dynamic amplification factor were taken into account. It was observed that corner columns can result in higher displacement that interior column. In addition upper column induced larger displacements than the base columns. Results also demonstrated that with decrease in duration of column removal, the strength of structure against collapse also decreases. Nastri et al. [13] applied friction connections in design of beam to column joints to improve the seicmic behavior of moment resisting frames. Using nonlinear and dynamic analyses the results indicated that equipped joints with friction connections exhibited satisfactory reduction of materials while observing the limit for drifts. Mahmoudi et al. [14] studied a replicable beam in mid-span where shear fuse at the end of this portion dissipates energy by shear yielding which leads to prevention of flexural yielding at the beams ends by weakening the mid-span of the beam. This technology enables the design of tall buildings' beams with smaller depth where according to design codes the minimum span to depth ratio must be satisfied. Jamshidiha et al. [15] evaluated the collapse probability of moment resisting frames with viscous dampers using 18 vector valued intensity measures. It was concluded that for respective frame the IM which is representative of spectral shape and ground motion duration effects can effectively and adequately predict the collapse of moment resisting frames with viscous dampers.

FEMA P695 [16] has proposed a rational method for evaluating the response modification factors of different seismic resisting systems, which demonstrates the safety margin against collapse. Zareian et al. [17] studied the seismic collapse performance of steel special moment frames using introduced criteria in FEMA P695 [16]. In summary, the results showed that although low- to -midrise structures designed with response spectrum analysis met the collapse criteria with considerable safety, long period structures failed to satisfy these criteria. Also in recent years, some scholars employed this methodology to assess and quantify SPFs of conventional structural systems [18-25].

Despite the comprehensive researches conducted on the impact of near-field earthquakes on structures and infrastructures, yet these effects have not been addressed properly though probabilistic methods to aid the codes and guidelines to have a better perspective of safety margin of buildings' collapse. As an instance, the effects of near-field grounds motions are not clearly mentioned in Iranian code of practice for seismic resistance design of buildings (Standard No. 2800) [26], the response modification factors for MRF systems introduced in this code should be evaluated properly. Due to the large number of moment resisting frame systems in seismic zones, most of which are in the vicinity of active faults, it is necessary to study the exact behavior of these structures under nearfield earthquakes.

In this regard, herein in the second section. A brief overview of FEMA P695 methodology is introduced with respect to the current performance objectives of design codes. It ought to be noticed that the motivation behind FEMA P695 approach is to supply a reasonable groundwork to specify seismic performance factors which will bring about a safe level against collapse in a seismic event, tantamount to what is expected by current seismic codes. In one sense, the collapse margin ratio, CMR, could be considered as the level of safety in a rare earthquake relative to a seismic event which can cause $50 \%$ of collapse. Having this information enables engineers to evaluate the safety of structures against collapse with respect to initial assumption for design parameters and helps to select suitable factors for considered hazard level which in result will lead to safer design. Following this, in section three, the procedure of selecting the index archetypes, nomenclature, design assumptions and loading are presented and at the end the results of design are indicated. In section four, assumptions related to nonlinear modeling of archetypes are presented. Also a verification is performed to compare the results with experimental test to validate numerical modeling in OpenSees. Section five presents the investigation on intermediate and special moment resisting frames using nonlinear pushover and incremental dynamic analyses to assess the seismic performance factors and collapse probability of these systems and compare them with acceptable criteria introduced in FEMA P695 methodology. The effects of site proximity to the faults are investigated with incremental dynamic analysis (IDA) using 22 far-field and 20 near-field records. Next, a comprehensive discussion between findings in this study and previous researches are reported in Sect. 6 which highlights the relevance and added value of this work. Finally, the aims and significance of research together with the main results of this study and recommendations for future studies are stated.

\section{Seismic performance evaluation according to FEMA P695 methodology}

To satisfy the Life Safety (LS) performance goal of design codes, FEMA P695 [16] proposed a methodology to assess the seismic performance factors based on the respective collapse probability of buildings. This goal is achieved by specifying an acceptably low probability of collapse under Maximum Considered Earthquake (MCE) ground motions. 
The process introduced in FEMA P695 for obtaining seismic performance factors involves three main stages. These stages include characterizing system behavior and determining index archetypes, developing numerical models of samples and running nonlinear static and dynamic analyses then evaluating assumed values of seismic performance factors of initial design stages according to the results of previous stage.

The nonlinear static analysis curve in Fig. 1 represents the seismic performance factors considered in the FEMA P695 approach using spectral coordinates. According to this figure, $100 \%$ of the effective seismic weight of the building, $W$, participates in the fundamental mode of structure at period of T. The response modification factor, $R$, is determined as the ratio of the MCE spectral acceleration $S_{\mathrm{MT}}$, to the base shear coefficient, $C_{\mathrm{s}}$ as follows:

$1.5 R=\frac{S_{\mathrm{MT}}}{C_{\mathrm{s}}}$

The overstrength factor, $\Omega$, for each structure is defined as the ratio of the maximum capacity of the fully-yielded system, $S_{\text {max }}$ to the base shear coefficient, $C_{s^{\prime}}$ as follows:

$\Omega=\frac{S_{\max }}{C_{s}}$

Incremental dynamic analysis (IDA) is employed to evaluate the median collapse capacity $\hat{S}_{\mathrm{CT}}$, of the structural systems for a presumed response modification factor. According to Fig. 1, collapse margin ratio, CMR, is defined as "the ratio of the median 5\%-damped spectral acceleration of the median collapse capacity $\hat{S}_{\mathrm{C} T}$, to the $5 \%$-damped spectral acceleration of the MCE ground motions, $S_{\mathrm{MT}}$, at



Fig. 1 Illustration of seismic performance factors as defined by the FEMA P695 Methodology [16] the fundamental period of the structure, $T^{\prime \prime}$ [16]. Spectral Shape Factor (SSF) is used to account for the effects of different ground motion records on the collapse margin ratio and to calculate the adjusted collapse margin ratio, ACMR, for each structural model. Acceptable performance is defined by the following two basic collapse prevention objectives [16]: "(1) the average adjusted collapse margin ratio $\left(\overline{A C M R}_{i}\right)$ for each performance group must be greater than the acceptable adjusted collapse margin ratio with accepting $10 \%$ of collapse probability $\left(\mathrm{ACMR}_{10 \%}\right)$ and (2) the adjusted collapse margin ratio $\left(\overline{\mathrm{ACMR}}_{\mathrm{i}}\right)$ for each index archetype must be greater than the acceptable adjusted collapse margin ratio with accepting $20 \%$ of collapse probability $\left(\mathrm{ACMR}_{20 \%}\right)^{\prime \prime}$. The variations of acceptable adjusted collapse margin ratios considering different total collapse uncertainty are depicted in Fig. 2 . According to this figure, by reducing the total collapse uncertainty from 60 to $40 \%$, the acceptable value of adjusted collapse margin ratio falls from 2.16 to 1.67 , which is effective in economic design. For validity of the presumed response modification factor, the calculated ACMR is required to be greater than the aforementioned collapse prevention objectives. Otherwise, the structural system must be reconsidered by adjusting the structural system design requirements, recharacterizing behavior, or redesigning with lower trial values of seismic performance factors.

\section{Preliminary design of archetypes}

In the first step of this methodology, to evaluate the seismic performance of moment resisting frames, it is necessary to define a range of archetypes that cover possible selections of this structural system for design. Therefore, steel moment resisting frame archetypes are developed in different performance groups corresponding to the height and the type of lateral resisting system. To this end, 5-,

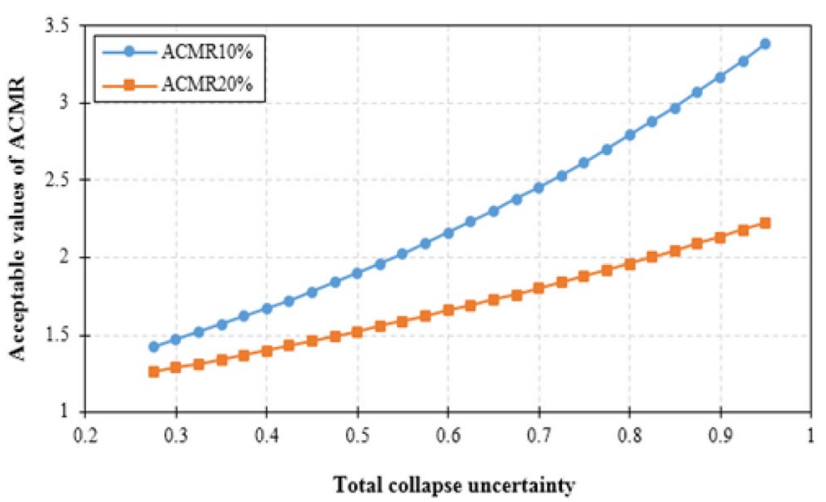

Fig. 2 Acceptable values of ACMR based on quantities of uncertainties (FEMA P695, Table 7-3) [16] 
10- and 15-story of Intermediate Moment Resisting Frame (IMRF) and Special Moment Resisting Frame (SMRF) are considered to reflect low-rise to high-rise buildings limited to $50.0 \mathrm{~m}$ as these systems are only applicable to this height range according to design codes such as ASCE7 [27] and Standard 2800 [26]. Then, these archetypes will be designed to conduct nonlinear static and dynamic analyses in the next steps to evaluate their seismic performances. A unique label is assigned to each archetype of performance group. In this label the first subscript represents number of stories and the second subscript indicates type of moment resisting frame e.g. Intermediate Moment Resisting Frame (IMRF) or Special Moment Resisting Frame (SMRF). For example, 5-IMRF represents the 5-story model with intermediate moment resisting frame as the lateral load resisting system. In addition, a new subscript will be added for IDA which indicates type of ground motion records, far-filed earthquakes or near-filed earthquakes. For example, 10-SMRF-NF represents the 10-story model with special moment resisting frame system as the lateral load resisting system which is subjected to Near-Field earthquakes.

The design load for archetypes are according to the provisions of Iranian Earthquake Resistance Design Code (Standard No. 2800) which is to a great extent similar to ASCE $7[26,27]$. In all structures, the soil-foundation-structure interaction is not considered and the connections to the base are supposed to be fixed. The buildings have a uniform story height of $3.2 \mathrm{~m}$ and include 4 bays of $5.0 \mathrm{~m}$ in each direction. It should be noted that spans of beams are limited to $5.0 \mathrm{~m}$ to meet the stiffness and inter-story drift limitations of building codes especially for slender archetype (15-story) and it is also a good representative of actual beam spans of buildings constructed in Tehran region which are the target buildings in the Standard 2800 . The plan layout and elevation view of the structures are shown in Fig. 3.

The design dead load was assumed to be $5.0 \mathrm{kN} / \mathrm{m}^{2}$ and the values of live and partition loads were considered as $2.0 \mathrm{kN} / \mathrm{m}^{2}$ and $1.0 \mathrm{kN} / \mathrm{m}^{2}$ for all stories, respectively. In all structures, columns and beams were made of steel grade 36 with $\mathrm{F}_{y}=250 \mathrm{MPa}$ and $\mathrm{F}_{u}=400 \mathrm{MPa}$. All beam-tocolumn connections are considered to be fully rigid so all columns are capable of transferring lateral loads as well as gravity loads simultaneously.

The load combinations for archetypes were considered in accordance with Section 12.4 of ASCE7 [27] and Load and Resistance Factor Design (LRFD) requirements of AISC 360 are applied to design columns and beams [28]. Design parameters for IMRF and SMRF archetypes are presented in Table 1. With respect to Standard No. 2800 the response modification factor for SMRF and IMRF buildings were considered 7.5 and 5.0, respectively [26]. It should be noted
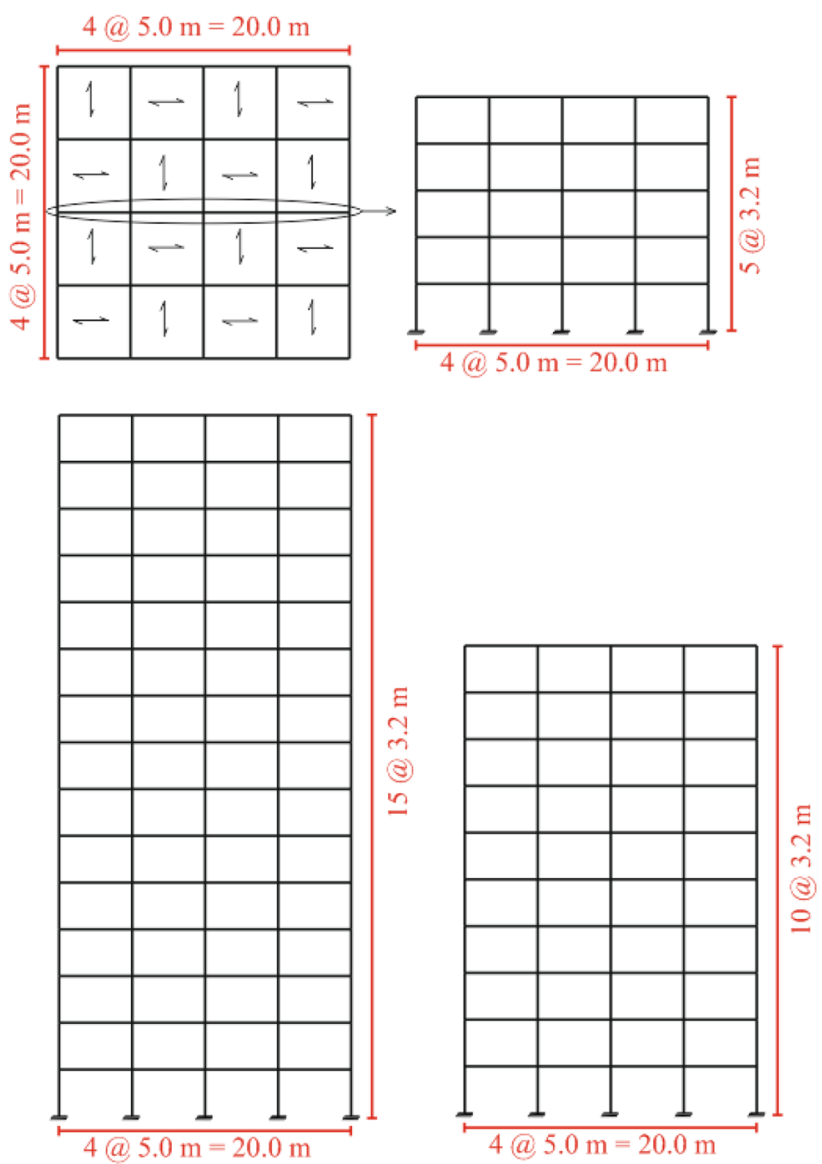

Fig. 3 Plan and elevation view of archetypes

that The " $R$ " value for SMRF system is considered 8.0 as per ASCE 7 [27]. Q is the seismic weight of structure, $T$ is approximate fundamental period, $T_{1}$ is natural period of structures obtained by Eigen value analysis and $V$ is design base shear. Designed beam and column sections for IMRF and SMRF archetypes are presented in Table 2. Built-up box sections and standard l-shaped sections are chosen for columns and beams, respectively. Width-to-thickness ratio of sections are limited to prevent local buckling of sections as prescribed in AISC 341 [29] for highly ductile members according to Table 1-8-1 of AISC 341. All structures are designed so that the inter-story drift ratios of floors do not exceed the allowable inter-story drift of 0.02 . In addition, the strong column-weak beam principle was satisfied for all connections in SMF structures.

\section{Nonlinear modeling and validation}

Skalomenos et al. [30] investigated the modeling level selection for the seismic analysis of frames with CFT columns. In this study, modeling level of sophistication 
Table 1 Design parameters for IMRF and SMRF archetypes

\begin{tabular}{|c|c|c|c|c|c|c|}
\hline \multirow[t]{3}{*}{ Archetype } & \multicolumn{6}{|c|}{ Key parameters } \\
\hline & \multirow[t]{2}{*}{ Approach } & \multicolumn{4}{|c|}{ Seismic design criteria } & \multirow[t]{2}{*}{ SMT (g) } \\
\hline & & $\mathrm{R}$ & $\mathrm{T}(\mathrm{Sec})$ & $\mathrm{T}_{1}(\mathrm{Sec})$ & V/W (g) & \\
\hline \multicolumn{7}{|l|}{ IMRF } \\
\hline 5-IMRF & Static & 5.0 & 0.64 & 1.34 & 0.14 & 1.05 \\
\hline 10-IMRF & Static & 5.0 & 1.07 & 1.87 & 0.09 & 0.67 \\
\hline 15-IMRF & Static & 5.0 & 1.46 & 2.36 & 0.07 & 0.54 \\
\hline \multicolumn{7}{|l|}{ SMRF } \\
\hline 5-SMRF & Static & 7.5 & 0.64 & 1.40 & 0.09 & 1.05 \\
\hline 10-SMRF & Static & 7.5 & 1.07 & 2.23 & 0.06 & 0.67 \\
\hline 15-SMRF & Static & 7.5 & 1.46 & 2.84 & 0.04 & 0.54 \\
\hline
\end{tabular}

were determined with respect to the behavior of columns, beams and panel zones with accordance to results of fragility curves. Based on these results, and outcomes of the study conducted by Macedo et al. [10] selection of the appropriate modeling level of sophistication can result in desired behavior of structures in a computationally efficient manner. In this regard, the modeling level of sophistication applied herein is very close to what are suggested for accurate modeling by previous researchers [10,30]. OpenSees software [31] is utilized to create nonlinear modelling of moment-resisting frame archetypes. Due to the symmetry of structure and loading, the 2D middle frame as indicated in Fig. $3 \mathrm{a}$ is considered for verification. To verify nonlinear modelling of momentresisting frames, a 2-story, 1-bay steel frame proposed by Laura Eads [32] is developed in OpenSees Software. The model proposed by Laura Eads is shown in Fig. 4a. Beams and columns are modelled using the "Elastic Beam-column Element" and nonlinear behavior of beams and columns are considered by rotational springs at their ends. Modified Ibarra-Medina-Krawinkler (Bilinear material) from the library of material in Open-Sees is assigned to rotational springs to capture the plastic hinges. Force-deformation relationship of flexural elements is shown in Fig. 4b. As a side note, general behavior of rotational springs used in beams and columns according to model proposed by Ibarra-Medina-Krawinkler is shown in Fig. 4c [33]. The experimental test results documented in their study have been utilized in ASCE/SEI 41 (Fig. 4b). Therefore, the modeling parameters for plastic hinges are obtained from ASCE/SEI 41 [34]. Parameters for columns are also derived from the respective code based on the ratio of imposed axial load to the total capacity. As indicated in Fig. 4a, a leaning column is modelled to consider the $P-\Delta$ effects on the moment resisting frames. The leaning columns are axially stiff, elastic, and pinned at the basement and story levels with no lateral stiffness. Corotational transformation is used to consider geometric nonlinearity. Floor masses were lumped into the end nodes of beams at each level.

Nonlinear responses of panel zones contribute considerably in values of displacements and plastic hinge distributions. Herein, the panel zones were modelled by the analytical models proposed by Gupta and Krawinkler [35] comprised of eight rigid elements which are connected with hinges at three corners with two bilinear rotational springs at the fourth corner (Fig. 5a). The trilinear shear force and shear distortion relationship for this model is shown in Fig. 5b.

The considered parameters for this model are as follows:

$V_{\mathrm{y}}=\frac{F_{\mathrm{y}}}{\sqrt{3}} A_{\mathrm{eff}} \approx 0.55 F_{\mathrm{y}} d_{c} t_{p}$

where $V_{y}$ is the panel zone shear yield strength, $F_{y}$ is the yield strength of steel material, $A_{\text {eff }}$ is the effective shear area, $d_{c}$ is the depth of the column and $t_{p}$ is the thickness of the web including any doubler plates. The elastic stiffness, $\mathrm{K}_{\mathrm{e}}$ of the panel zone and the corresponding yield distortion are:

$K_{e}=\frac{V_{y}}{\gamma_{y}}=0.95 d_{c} t_{p} G$

$\gamma_{y}=\frac{F_{y}}{\sqrt{3} G}$

where $\mathrm{G}$ is the shear modules of the column material.

Post Shear resistance of panel zone after yielding, $\mathrm{V}_{\mathrm{p}^{\prime}}$ which is referred to the full plastic shear resistance of the joint can be calculated as:

$V_{p}=V_{y}\left(1+\frac{3 K_{p}}{K_{e}}\right) \approx 0.55 F_{y} d_{c} t_{p}\left(1+\frac{3 b_{c} t_{c f}^{2}}{d_{b} d_{c} t_{p}}\right)$ 
Table 2 Section sizes for archetypes

\begin{tabular}{|c|c|c|c|c|c|c|}
\hline \multirow[t]{3}{*}{ Floor No } & \multicolumn{6}{|l|}{ IMRF } \\
\hline & \multicolumn{3}{|l|}{ Columns } & \multicolumn{3}{|l|}{ Beams } \\
\hline & 5-IMRF & 10-IMRF & 15-IMRF & 5-IMRF & 10-IMRF & 15-IMRF \\
\hline 1 & $35 \times 1.5$ & $50 \times 1.5$ & $55 \times 2.0$ & IPE400 & IPE450 & IPE500 \\
\hline 2 & $35 \times 1.5$ & $50 \times 1.5$ & $55 \times 2.0$ & IPE400 & IPE450 & IPE500 \\
\hline 3 & $30 \times 1.0$ & $50 \times 1.5$ & $55 \times 2.0$ & IPE360 & IPE450 & IPE500 \\
\hline 4 & $25 \times 1.0$ & $40 \times 1.5$ & $50 \times 1.5$ & IPE360 & IPE450 & IPE450 \\
\hline 5 & $25 \times 1.0$ & $40 \times 1.5$ & $50 \times 1.5$ & IPE270 & IPE450 & IPE450 \\
\hline 6 & & $40 \times 1.5$ & $50 \times 1.5$ & & IPE400 & IPE450 \\
\hline 7 & & $35 \times 1.5$ & $45 \times 1.5$ & & IPE400 & IPE450 \\
\hline 8 & & $35 \times 1.0$ & $45 \times 1.5$ & & IPE360 & IPE450 \\
\hline 9 & & $35 \times 1.0$ & $45 \times 1.5$ & & IPE330 & IPE450 \\
\hline 10 & & $35 \times 1.0$ & $40 \times 1.5$ & & IPE270 & IPE450 \\
\hline 11 & & & $40 \times 1.5$ & & & IPE450 \\
\hline 12 & & & $40 \times 1.5$ & & & IPE400 \\
\hline 13 & & & $35 \times 1.0$ & & & IPE360 \\
\hline 14 & & & $35 \times 1.0$ & & & IPE330 \\
\hline 15 & & & $35 \times 1.0$ & & & IPE270 \\
\hline \multirow[t]{3}{*}{ Floor No } & \multicolumn{6}{|l|}{ SMRF } \\
\hline & \multicolumn{3}{|l|}{ Columns } & \multicolumn{3}{|l|}{ Beams } \\
\hline & 5-SMRF & 10-SMRF & 15-SMRF & 5-SMRF & 10-SMRF & 15-SMRF \\
\hline 1 & $30 \times 2.0$ & $40 \times 2.5$ & $40 \times 2.5$ & IPE400 & IPE400 & IPE450 \\
\hline 2 & $30 \times 2.0$ & $40 \times 2.5$ & $40 \times 2.5$ & IPE400 & IPE400 & IPE450 \\
\hline 3 & $25 \times 1.5$ & $40 \times 2.5$ & $40 \times 2.5$ & IPE360 & IPE400 & IPE450 \\
\hline 4 & $25 \times 1.5$ & $35 \times 2.0$ & $35 \times 2.0$ & IPE360 & IPE400 & IPE450 \\
\hline 5 & $25 \times 1.5$ & $35 \times 2.0$ & $35 \times 2.0$ & IPE270 & IPE400 & IPE450 \\
\hline 6 & & $35 \times 2.0$ & $35 \times 2.0$ & & IPE400 & IPE450 \\
\hline 7 & & $25 \times 2.0$ & $35 \times 2.0$ & & IPE400 & IPE450 \\
\hline 8 & & $25 \times 2.0$ & $35 \times 2.0$ & & IPE360 & IPE450 \\
\hline 9 & & $25 \times 1.5$ & $35 \times 2.0$ & & IPE330 & IPE450 \\
\hline 10 & & $25 \times 1.5$ & $30 \times 2.0$ & & IPE270 & IPE450 \\
\hline 11 & & & $30 \times 2.0$ & & & IPE450 \\
\hline 12 & & & $30 \times 2.0$ & & & IPE400 \\
\hline 13 & & & $25 \times 2.0$ & & & IPE360 \\
\hline 14 & & & $25 \times 2.0$ & & & IPE300 \\
\hline 15 & & & $25 \times 2.0$ & & & IPE270 \\
\hline
\end{tabular}

All dimensions are in $\mathrm{cm}$

where $\mathrm{K}_{\mathrm{p}}$ is the post-yield stiffness, $\mathrm{b}_{\mathrm{c}}$ is the width of the column flange and $t_{c f}$ is the thickness of the column flange.

Since it was assumed that the connections of beams to columns are fully restrained and the occurrence of localized failure modes are avoided by applying proper design and detailing, therefore the behavior of beam-tocolumn connections were not incorporated in nonlinear component models. Newmark method with parameters of $\gamma=0.5$ and $\beta=0.25$ is used for nonlinear dynamic analysis. The proposed model by Laura Eads is subjected to the Canoga Park record from the 1994 Northridge earthquake [32]. The floor displacement time history under Canoga Park record in [32] is compared with the numerical model developed in this study as shown in Fig. 6. This figure represents satisfactory agreement between the model proposed by Laura Eads and OpenSees model in the present study.

Eventually, Results of modal analyses in Table 3 represents a good agreement between the 2D and 3D archetypes and ensured conducting nonlinear analyses on 2D 




(a)



(b)



(c)

Fig. 4 a The model proposed by Laura Eads [32]. b Moment-rotation relationship of flexural elements [34] c General behavior of rotational springs used in beams and columns [33]

Fig. 5 a Analytical model for a panel zone. b Trilinear shear force and shear distortion relationship for panel zone using two rotational springs [35]

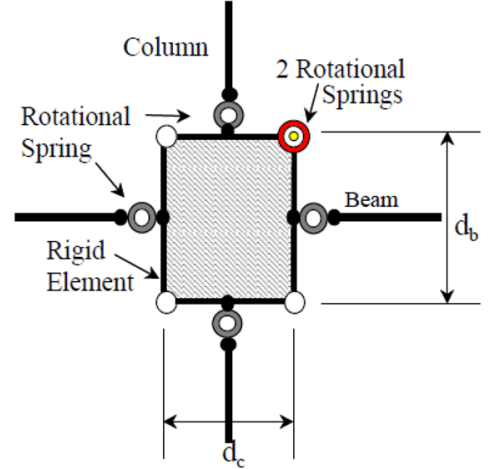

(a)

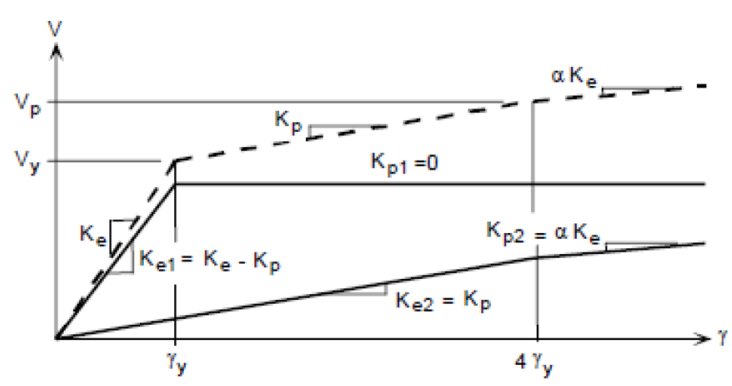

(b) 
Fig. 6 a Floor displacement history based on a study conducted by Laura Eads subjected to the Canoga Park record [32]. b Floor displacement history obtained in the present study
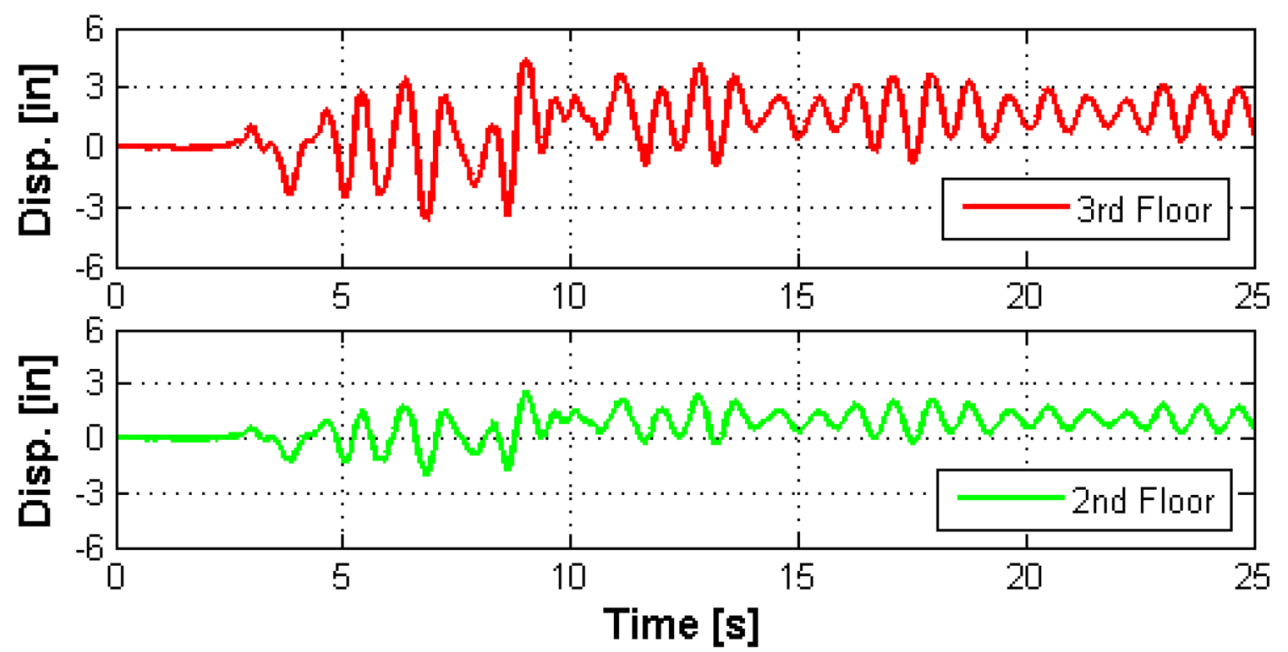

(a)
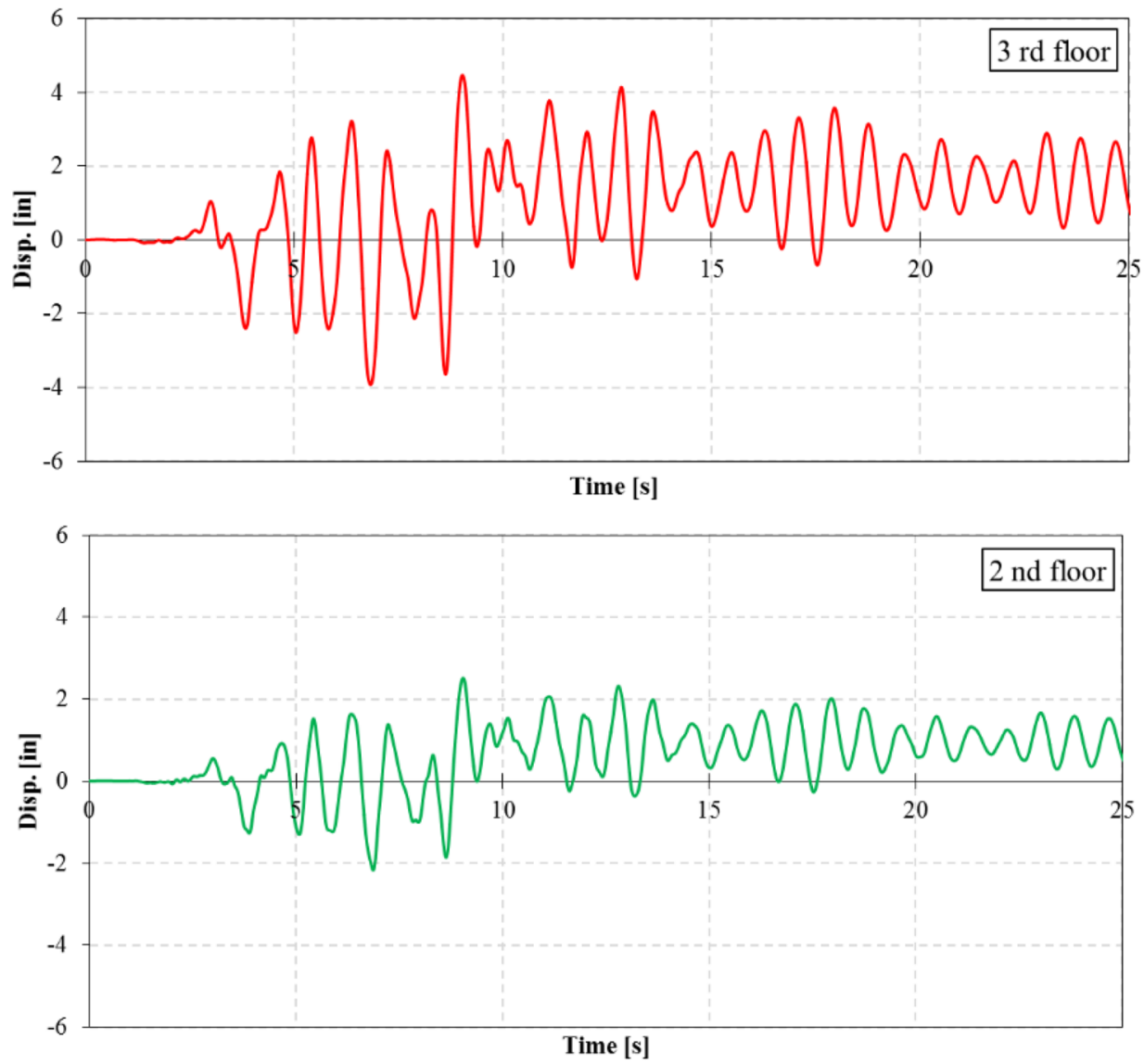

(b)

models. In addition, Rayleigh damping theory is considered with $5 \%$ structural damping ratio.

As a side note, different mechanisms contribute to dissipating energy in a structure under a seismic loading. It is common that viscous damping represents dissipation of "elastic" energy and damping for nonlinear responses are embedded in cyclic behaviors of elements.
Thus, the overall amount of dissipated energy can be calculated as sum of elastic and inelastic energies dissipated throughout a seismic loading. In this study elastic damping is applied using Rayleigh damping. In Rayleigh damping a damping matrix are defined as below [36]: 
Table 3 Comparison of period of vibrations for the archetypes

\begin{tabular}{|c|c|c|c|c|c|c|}
\hline \multirow[t]{2}{*}{ Archetypes } & \multicolumn{3}{|l|}{ 3D model } & \multicolumn{3}{|l|}{ 2D model } \\
\hline & 1 st mode & 2nd mode & 3 rd mode & 1 st mode & 2nd mode & 3rd mode \\
\hline 5-IMRF & 1.285 & 0.423 & 0.239 & 1.34 & 0.469 & 0.289 \\
\hline 5-SMRF & 1.176 & 0.415 & 0.236 & 1.40 & 0.485 & 0.285 \\
\hline 10-IMRF & 1.891 & 0.716 & 0.401 & 1.87 & 0.705 & 0.404 \\
\hline 10-SMRF & 2.174 & 0.81 & 0.462 & 2.23 & 0.848 & 0.49 \\
\hline 15-IMRF & 2.351 & 0.891 & 0.532 & 2.36 & 0.894 & 0.54 \\
\hline 15-SMRF & 2.622 & 0.993 & 0.593 & 2.84 & 1.073 & 0.645 \\
\hline
\end{tabular}

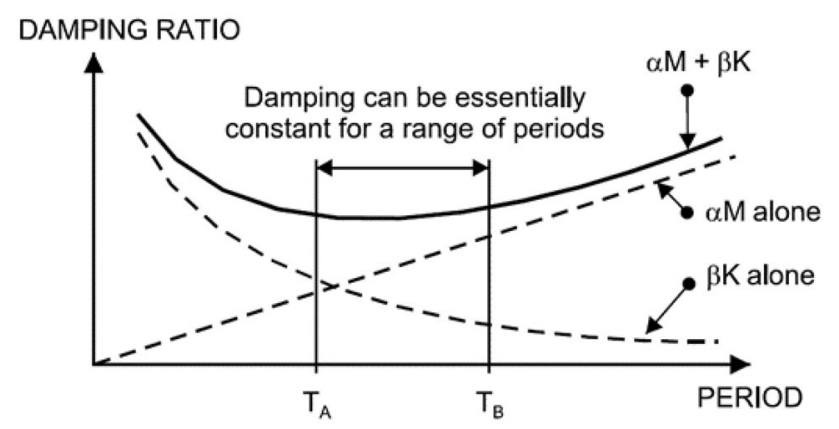

Fig. 7 Variation of damping ratio with period for linear analysis

$C=\alpha M+\beta K$

where $M$ is the mass matrix, $K$ is the initial elastic stiffness matrix, $\alpha$ and $\beta$ are multiplying factors. According to Rayleigh Damping, the damping ratio is determined based on only 2 modes. The damping ratio for other modes is obtained as shown in the Fig. 7. The relationship between damping ratio and mode period is:

$\zeta_{i}=\alpha \frac{T_{l}}{4 \pi}+\alpha \frac{\pi}{T_{i}}$

$\alpha=4 \pi \zeta \frac{1}{\left(T_{i}+T_{j}\right)}$

$\beta=\frac{\zeta}{\pi} \frac{T_{i} T_{j}}{\left(T_{i}+T_{j}\right)}$

where $\mathrm{Ti}$ is period of mode $\mathrm{i}$ and $\zeta$ is the proportion of critical damping in this mode.

Materials deeply affect the rate of damping in structures, however, for most investigations it is common to assume that $5 \%$ of critical damping is suitable for buildings.

According to Powell's studies [36], it is suggested that "if two period ratios are specified so that $\frac{T_{A}}{T_{1}}=0.25$ and $\frac{T_{B}}{T_{1}}=0.9$ and the critical damping to be chosen $5.0 \%$, where
$T_{1}$ is the first mode period, then the damping will be obtained close to $5.0 \%$ over a range of periods from $0.2 \mathrm{~T}_{1}$ to $T_{1}$ which covers the most important modes".

\section{Analysis results}

\subsection{Nonlinear static analysis}

Nonlinear static analysis was performed on each archetype in order to calculate the overstrength factors, periodbased ductility and investigate the nonlinear behavior of archetypes. The key point in performing a nonlinear static analysis is to determine the ultimate displacement for archetypes. In this study, based on the FEMA P695 [16] guidelines, if the strength of an archetype drops to $80 \%$ of the maximum resistance of structure $\left(\mathrm{V}=0.8 \mathrm{~V}_{\max }\right)$, the displacement corresponded to the $80 \%$ of maximum strength is selected as the ultimate displacement of archetype $\left(\delta_{\mathrm{u}}\right)$. The lateral load pattern was exerted according to the first transitional mode shape of each archetype. The pushover curves of archetypes are shown in Fig. 8. It can be inferred that, the maximum lateral resistance of the SMF buildings is considerably higher compared to the ultimate strength of IMF structures. It also can be observed that with the increase in structural height, lateral bearing capacity of moment resisting systems also rises.

Table 4 shows the results of nonlinear static analysis for each archetype. The over-strength factor $(\Omega)$ are calculated as:

$\Omega=V_{\text {Max }} / V$

where $\mathrm{V}_{\text {Max }}$ and $\mathrm{V}$ are the maximum base shear capacity and design base shear, respectively. The period-based ductility factor $\left(\mu_{\mathrm{T}}\right)$ is calculated as the ratio of ultimate roof displacement, $\delta_{u}$, to the effective yield roof displacement, $\delta_{y, \text { eff }}$ as follows:

$\mu_{T}=\delta_{u} / \delta_{y, e f f}$

The maximum roof displacement, $\delta_{u}$, is defined as the roof displacement in which a drop of $20 \%$ of the 



Fig.8 Pushover curves of archetypes

Table 4 Pushover results

\begin{tabular}{lccccc}
\hline Archetype & \multicolumn{5}{l}{ Nonlinear static analyses results } \\
\cline { 2 - 6 } & $\delta_{y, \text { eff }}(\mathrm{m})$ & $\delta_{\mathrm{u}}(\mathrm{m})$ & $\mathrm{V}_{\text {Max }}(\mathrm{KN})$ & $\mu_{\mathrm{T}}$ & $\Omega$ \\
\hline IMRF & & & & & \\
5-IMRF & 0.20 & 0.58 & 1120 & 2.82 & 2.50 \\
10-IMRF & 0.29 & 1.1 & 1640 & 3.85 & 2.83 \\
15-IMRF & 0.25 & 0.93 & 1300 & 3.67 & 1.89 \\
Average & - & - & - & 3.45 & 2.40 \\
SMRF & & & & & \\
5-SMRF & 0.26 & 1.11 & 1280 & 4.35 & 4.31 \\
10-SMRF & 0.44 & 1.90 & 1770 & 4.28 & 4.61 \\
15-SMRF & 0.53 & 1.77 & 1890 & 3.32 & 4.11 \\
Average & - & - & - & 3.98 & 4.34 \\
\hline
\end{tabular}

maximum base shear capacity is observed. The parameter $\delta_{y, \text { eff }}$ is calculated as:

$\delta_{y, \text { eff }}=C_{0} \frac{V_{M a x}}{V}\left(\frac{g}{4 \pi^{2}}\right)\left(\max \left(T, T_{1}\right)\right)^{2}$

In which, $\mathrm{W}$ is the building weight, $\mathrm{g}$ is the gravity constant, $\mathrm{T}$ is the approximate fundamental period obtained using Section $\$ 5.2 .5$ of FEMA P695 guideline, $T_{1}$ is the analytical fundamental period calculated using the eigenvalue analysis. Also the coefficient $C_{0}$ relates fundamental-mode
(SDOF) displacement to roof displacement of multiple degree of freedom (MDOF) and is calculated as:

$C_{0}=\Phi_{1, r} \frac{\sum_{1}^{N} m_{x} \Phi_{1, x}}{\sum_{1}^{N} m_{x} \Phi_{1, x}^{2}}$

where $m_{x}$ is the mass at level $x$, and $\varnothing_{1, x}\left(\varnothing_{1, r}\right)$ is the ordinate of the fundamental mode at level $x$ (roof), and $N$ is the number of levels.

As shown in this table, While the effective yield displacement $\left(\delta_{y, \text { eff }}\right)$ of SMF structures are slightly higher than those of IMF system, the ultimate displacement $\left(\delta_{\mathrm{u}}\right)$ of these systems are in some cases twice as large as corresponded values for intermediate moment frame archetypes. In addition to this, as the height of the structures increases, the ductility coefficient $\mu$ decreases. For example, the ductility coefficient for the 5-SMF structure was 4.35, while for the 15-SMF structure it decreased by 3.32 . On the other hand, by comparing the ductility coefficient of IMF and SMF archetypes, it is observed that the average of ductility coefficients in SMF structures are higher than that of IMF group which lies in the limitation of the width-to-thickness ratio in the SMF system as compared to the IMF.

Investigation on the overstrength factor indicated that increase in the height of the structures leads to decrease in the over-strength factor $(\Omega)$. For example, this coefficient 
for the 5-IMF structure was 2.50, while for the 15-IMF structure it decreased to 1.89 . Finally, Comparison of special and intermediate moment resisting frames shows that the average of over-strength factor in SMF structures are significantly higher than that of IMF.

\subsection{Incremental dynamic analysis (far-field and near-field earthquakes)}

In this section, structures are analyzed by two sets of nearfield and far-field records introduced in FEMA P695 [37] in order to study the nonlinear behavior of archetypes. These analyses are performed to obtain the median collapse capacity $\left(\hat{S}_{C T}\right)$ and the collapse margin ratio (CMR) of structures. The median collapse capacity indicates the intensity at which more than half of the records cause the structures to collapse.

In the IDA analysis method, a series of nonlinear dynamic analyses are performed for each seismic record in order to accurately estimate the complete response range (from the elastic phase to the yielding state and then the nonlinear phase and ultimately to the overall structural instability). In terms of selection of ground motions for nonlinear dynamic analysis, lervolino and Monfaredi [38] reviewed the seismic input parameters which affects the probabilistic assessment (e.g. the number of records and their intensity) and discussed the advantages and disadvantages of introduced procedures for selection of suitable ground motion records. However, in this study ground motion records are selected based on the FEMA P695 methodology which should meet a number of conflicting objectives [16] and is consistent with performance objectives of the FEMA P695 and ground motion requirements of ASCE 7 [27]. Also these ground motion records were used in a number of investigation tasks with the aim of collapse assessment of structures. Therefore, Herein, 22 individual far-field records and 20 near-field records are used. The records were scaled in two steps before they were used in IDA. In the first step, each records were scaled so that their peak ground velocities reach one. Next, they were entirely scaled upward or downward at the fundamental period of the archetype to match the MCE spectral acceleration. The next step in this approach is to process the results of the analysis, which results in plotting the IDA curves. In These plots, the vertical axis represents the spectral intensity of the ground motions as the intensity measure (IM) and the horizontal axis represents maximum inter-story drift ratio as the engineering demand parameter recorded in each time history analysis.

The results of this section will be based on plotting the fragility curves and calculating the median collapse capacity. Despite the symmetry in the structure plan, incremental nonlinear dynamic analyses were performed on the structure in one direction. Tables 5 and 6 illustrate the characteristics of these records. Given the number of records used, approximately 10,000 nonlinear dynamic analyses were performed to draw the IDA curves.

Figures 9 and 10 illustrate the IDA and median curves for SMF and IMF structures under far-field and near-field earthquakes. According to Vamvatsikos and Cornell [39], the collapse point is determined as the intensity of the ground motions result in the maximum inter-story drift of $10 \%$ or where the local tangent of IDA curve reaches $20 \%$ of the elastic slope. In this study, the maximum inter-story drift of $10 \%$ was used as the collapse point in analyses. Comparison of IDA and median curves shows that under both far-field and near-field records with the increase in the height of IMRF and SMRF structures, collapse of structures happened at lower accelerations. On the other hand, by comparing IMRF and SMRF archetypes with the same height, it is observed that the capacity of SMRF system against collapse is higher than the IMRF. The point in comparing the capacity of frames under near-field and far-field record sets is that the acceleration corresponded to the collapse point of IMRF and SMRF structures are further reduced when they are under near-field earthquakes.

Fragility curves represent the probability of collapse of structures in terms of earthquake characteristics and other design parameters, thereby it enables investigation on the seismic vulnerability of the structure. From the IDA curves mentioned in the previous section a spectral acceleration value corresponding to the collapse point of the investigated structure was extracted and then the fragility curve can be plotted in a graph through a cumulative distribution function in terms of spectral acceleration to the probability of collapse. Figures 11 and 12 show the fragility curves obtained for IMRF and SMRF structures under farfield and near-field earthquakes, respectively.

During this procedure, different uncertainties influence the collapse capacity of structures. The sources of uncertainties in FEMA P695 include record-to-record $\left(\beta_{R T R}\right)$ uncertainty, design requirement $\left(\beta_{D R}\right)$ uncertainty, test data $\left(\beta_{T D}\right)$ uncertainty, and modelling $\left(\beta_{M D L}\right)$ uncertainty. The value of RTR uncertainty, $\beta_{R T R}$ accounts for variability of ground motions which is related to the periodbased ductility as follows:

$0.2 \leq \beta_{R T R}=0.1+0.1 \mu_{T} \leq 0.4$

According to FEMA P695 methodology, $\beta_{D R}, \beta_{T D}$ and $\beta_{\mathrm{MDL}}$ are determined based on four levels of superior, good, fair and poor with quantitative scales of 0.1, 0.2, 0.35 and 0.5 , respectively. In addition, the total collapse uncertainty, $\beta_{\mathrm{TOT}}$ is calculated as Eq. (16) assuming uncertainties to be independent. 
Table 5 Characteristics of far-field record set used in IDA [37]

\begin{tabular}{|c|c|c|c|c|c|c|c|}
\hline ID No & Name & Year & Magnitude & Station & $\begin{array}{l}\text { Site class } \\
\text { (NEHRP) }\end{array}$ & $P G A_{\max }(g)^{a}$ & $P G V_{\text {max }}(\mathrm{cm} / \mathrm{s})^{\mathrm{a}}$ \\
\hline 1 & Northridge & 1994 & 6.7 & Beverly hills & $\mathrm{D}$ & 0.52 & 63 \\
\hline 2 & Northridge & 1994 & 6.7 & Canyon country-WLC & $\mathrm{D}$ & 0.48 & 45 \\
\hline 3 & Duzce, Turkey & 1999 & 7.1 & Bolu & $\mathrm{D}$ & 0.82 & 62 \\
\hline 4 & Hector Mine & 1999 & 7.1 & Hector & $\mathrm{C}$ & 0.34 & 42 \\
\hline 5 & Imperial valley & 1979 & 6.5 & El Centro array \# 11 & $\mathrm{D}$ & 0.38 & 33 \\
\hline 6 & Imperial valley & 1979 & 6.5 & Delta & $\mathrm{D}$ & 0.35 & 42 \\
\hline 7 & Kobe, Japan & 1995 & 6.9 & Nishi-Akashi & $\mathrm{C}$ & 0.51 & 37 \\
\hline 8 & Kobe, Japan & 1995 & 6.9 & Shin-Osaka & $\mathrm{D}$ & 0.24 & 38 \\
\hline 9 & Kocaeli, Turkey & 1999 & 7.5 & Duzce & $\mathrm{D}$ & 0.36 & 59 \\
\hline 10 & Kocaeli, Turkey & 1999 & 7.5 & Arcelik & $\mathrm{C}$ & 0.22 & 40 \\
\hline 11 & Landers & 1992 & 7.3 & Yermo Fire Station & $\mathrm{D}$ & 0.24 & 52 \\
\hline 12 & Landers & 1992 & 7.3 & Coolwater & $\mathrm{D}$ & 0.42 & 42 \\
\hline 13 & Loma Prieta & 1989 & 6.9 & Capitola & $\mathrm{D}$ & 0.53 & 35 \\
\hline 14 & Loma Prieta & 1989 & 6.9 & Gilroy Array \# 3 & $\mathrm{D}$ & 0.56 & 45 \\
\hline 15 & Manjil, Iran & 1990 & 7.4 & Abbar & $\mathrm{C}$ & 0.51 & 54 \\
\hline 16 & Superstition Hills & 1987 & 6.5 & El Centro Imp. Co. Cent & $\mathrm{D}$ & 0.36 & 46 \\
\hline 17 & Superstition Hills & 1987 & 6.5 & Poe Road & $\mathrm{D}$ & 0.45 & 36 \\
\hline 18 & Cape Mendocino & 1992 & 7.0 & Rio dell overpass & $\mathrm{D}$ & 0.55 & 44 \\
\hline 19 & Chi-Chi Taiwan & 1999 & 7.6 & CHY101 & $\mathrm{D}$ & 0.44 & 115 \\
\hline 20 & Chi-Chi Taiwan & 1999 & 7.6 & TCU045 & $\mathrm{C}$ & 0.51 & 39 \\
\hline 21 & San Fernando & 1971 & 6.6 & LA-Hollywood Stor FF & $\mathrm{D}$ & 0.21 & 19 \\
\hline 22 & Friuli, Italy & 1976 & 6.5 & Tolmezzo & C & 0.35 & 31 \\
\hline
\end{tabular}

$\beta_{\mathrm{TOT}}=\sqrt{\beta_{\mathrm{RTR}}^{2}+\beta_{\mathrm{DR}}^{2}+\beta_{\mathrm{TD}}^{2}+\beta_{\mathrm{MDL}}^{2}}$

In this study, the requirements of ANSI/AISC 360 and ANSI/AISC 341 were used to design structures. Therefore, due to the robustness and high confidence level of these design requirements, a quality rating of superior equal to 0.1 was selected for design requirement uncertainty. In lieu of relationships derived from experiment or analysis, the generalized force-deformation curve of ASCE 41 was used for nonlinear modeling of components and well captured the structural collapse behavior. Therefore, a quality raring of good equal to 0.2 was considered for both test data and modeling uncertainty $[17,40]$. The total collapse uncertainty, $\beta_{\mathrm{TOT}}$ is calculated equal to 0.5 as presented in Table 7.

It can be found from fragility curves considering all uncertainties that under Maximum Considered Earthquake intensity $\left(\hat{S}_{M T}\right)$, the collapse probability of SMRF structures is $2.5,6.3,8.2$ and $10,6.2,15 \%$ under both far-field and near-field records, respectively. However, the same values for IMRF system are 25, 29, 40\% and 32, $40 \%, 46 \%$ under far-field and near-field ground motion records, respectively.
By dividing the median collapse capacity values $\left(\hat{S}_{C T}\right)$ to the maximum spectral acceleration $\left(\hat{S}_{M T}\right)$, the collapse margin ratios (CMR) for each structure obtain according to Eq. 17. The results of the median collapse capacity $\left(\hat{S}_{C T}\right)$ and the collapse margin ratio (CMR) resulting from the near-field and far-field records are shown in Table 8, respectively.

$C M R=\frac{\hat{S}_{C T}}{S_{M T}}$

In both types of systems, as the height of structures increases the collapse margin ratio (CMR) decreases which is due to reduction in the median collapse capacity $\left(\hat{S}_{C T}\right)$. The mean CMR parameters were $1.47,3.19,1.22$ and 2.51 for PG-1, PG-2, PG-3 and PG-4, respectively. It can be found that the collapse margin ratios in SMF archetypes are over twice than those of IMRF counterparts under both far-field and near-field earthquakes. The average values of CMR show that for the IMRF structures the average CMR value in near-fault earthquakes was reduced by about $17 \%$ compared to far-field earthquakes. Whereas for SMRF structures, the average of CMR 
Table 6 Characteristics of near-field record set used in IDA [37]

\begin{tabular}{|c|c|c|c|c|c|c|c|}
\hline ID No & Name & Year & Magnitude & Station & $\begin{array}{l}\text { Site class } \\
\text { (NEHRP) }\end{array}$ & $P G A_{\max }(g)^{a}$ & $P G V_{\text {max }}(\mathrm{cm} / \mathrm{s})^{\mathrm{a}}$ \\
\hline \multicolumn{8}{|c|}{ Pulse records subset } \\
\hline 1 & Imperial Valley-06 & 6.5 & 1979 & El Centro Array \# 6 & $\mathrm{D}$ & 0.44 & 111 \\
\hline 2 & Imperial Valley-06 & 6.5 & 1979 & El Centro Array \# 6 & $\mathrm{D}$ & 0.46 & 108 \\
\hline 3 & Irpinia, Italy-01 & 6.9 & 1980 & Stumo & B & 0.31 & 45 \\
\hline 4 & Superstition Hills-02 & 6.5 & 1987 & Parachute test site & $\mathrm{D}$ & 0.42 & 106 \\
\hline 5 & Loma Prieta & 6.9 & 1989 & Saratoga-Aloha & $\mathrm{C}$ & 0.38 & 55 \\
\hline 6 & Cape Mendocino & 7.0 & 1992 & Petrolia & $\mathrm{C}$ & 0.63 & 82.1 \\
\hline 7 & Landers & 7.3 & 1992 & Lucerne & $\mathrm{C}$ & 0.79 & 140 \\
\hline 8 & Northridge-01 & 6.7 & 1994 & Rinadi Receiving Sta & $\mathrm{D}$ & 0.87 & 167 \\
\hline 9 & Northridge-01 & 6.7 & 1994 & Sylmar-Olive view & $\mathrm{C}$ & 0.73 & 122 \\
\hline 10 & Kocaeli, Turkey & 7.5 & 1999 & Izmit & B & 0.22 & 29 \\
\hline 11 & Chi-Chi, Taiwan & 7.6 & 1999 & TCU065 & $\mathrm{D}$ & 0.82 & 127 \\
\hline 12 & Chi-Chi, Taiwan & 7.6 & 1999 & TCU102 & $\mathrm{C}$ & 0.29 & 106 \\
\hline \multicolumn{8}{|c|}{ No Pulse Records Subset } \\
\hline 13 & Imperial Valley-06 & 6.5 & 1979 & Bonds Corner & $\mathrm{D}$ & 0.76 & 44 \\
\hline 14 & Imperial Valley-06 & 6.5 & 1979 & Chihuahua & $\mathrm{D}$ & 0.28 & 30 \\
\hline 15 & Nahanni, Canada & 6.8 & 1985 & Site 2 & $\mathrm{C}$ & 0.45 & 34 \\
\hline 16 & Loma Priesta & 6.9 & 1989 & BRAN & $\mathrm{C}$ & 0.64 & 55 \\
\hline 17 & Loma Priesta & 6.9 & 1989 & Corralitos & $\mathrm{C}$ & 0.51 & 45 \\
\hline 18 & Northridge-01 & 6.7 & 1994 & LA-Sepulveda VA & $\mathrm{C}$ & 0.73 & 70 \\
\hline 19 & Northridge-01 & 6.7 & 1994 & Northridge-Saticoy & $\mathrm{D}$ & 0.42 & 53 \\
\hline 20 & Chi-Chi, Taiwan & 7.6 & 1999 & TCU067 & C & 0.56 & 91 \\
\hline
\end{tabular}

value in near-fault earthquakes has decreased by $21 \%$ compared to far-field earthquakes which indicate the vulnerability of structures under near-field earthquakes.

The collapse capacity values $\left(\hat{S}_{C T}\right)$ and the collapse margin ratio (CMR) of the structures depend on the frequency content of the earthquakes. To account for this effect, the SSF value will be multiplied in the CMR value to obtain the adjusted collapse margin ratio parameter (ACMR). SSF coefficient is a function of period, ductility and seismic group. The ACMR values for each of archetypes are obtained from the following equation:

$\mathrm{ACMR}=\mathrm{SSF} \times \mathrm{CMR}$

The spectral shape factor (SSF) considers frequency content of the ground motion records which depends on the fundamental period of structure, $T$, the period based ductility, $\mu_{T}$, and the seismic design category. The SSF is determined as follows:

$\mathrm{SSF}=\exp \left(\beta_{1} \times\left(\bar{\varepsilon}_{0}(T)-\bar{\varepsilon}(T)_{\text {records }}\right)\right)$

where:
$\beta_{1}=(0.14)\left(\mu_{T}-1\right)^{0.42} \leq 0.317$

$0 \leq \bar{\varepsilon}(T)_{\text {records }}=(0.6)(1.5-T) \leq 0.6$

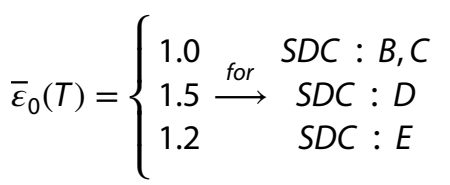

Based on FEMA P695, $\beta$, depends on the building inelastic deformation capacity. $\bar{\varepsilon}(\mathrm{T})_{\text {records }}$ is for the far-field record sets and $\bar{\varepsilon}_{0}$ depends on the Seismic Design Category $\left(\mathrm{SDC}\right.$ ) from $S D C_{B}$ to $S D C_{E}$ indicating the lowest to highest seismicity, respectively.

In order to evaluate the response modification factor introduced in the Iranian code of practice for seismic resistance design of buildings (Standard No. 2800), the value of adjusted collapse margin ratio for each performance group $\left(\overline{A C M R_{i}}\right)$ and for each archetypes $\mathrm{ACMR}_{i}$ should be greater than $\mathrm{ACMR}_{10 \%}$ and $A C M R_{20 \%}$, respectively. Table 9 presents all the related parameters for the collapse assessment of IMRF and SMRF structures resulted from nonlinear static analyses and dynamic analyses under 



Fig. 9 IDA curves for IMRF and SMRF structures under far-field earthquakes

far-field and near-field earthquakes. As shown in this table, the values of $\mathrm{ACMR}_{i}$ and $\overline{\mathrm{ACMR}_{i}}$ for each of PG-1 and PG-2 are greater than the required value of 1.52 and 1.90 , respectively. Thus, The structural system of intermediate moment frame (IMRF) and special moment frame (SMRF) satisfy the requirements of acceptance according to FEMA P695 methodology [37]. Therefore, the response modification factor (R) of 5.0 and 7.5 recommended in Iranian Code Standard No. 2800 [26] are suitable for IMRF and SMRF structures under far-field earthquakes and the use of this coefficient in design will ensure the life safety of residents. On the other hand, as it can be seen in this table, PG-3 did not satisfy the requirements under near-field earthquakes, hence using IMRF system based on the design criteria in the Standard No. 2800 code is not recommended for design of buildings near the faults. However the values of $\mathrm{ACMR}_{i}$ and $\overline{\mathrm{ACMR}}$, for $\mathrm{PG}-4$ are greater than the required value of 1.52 and 1.90 , respectively. Therefore, SMF system can be constructed in areas near the fault with respect to the seismic requirements of FEMA P695.

It is also apparent that the average of the adjusted collapse margin ratio (ACMR) for SMRF buildings turned out to be twice greater than those of IMRF buildings in both near-field and far-field records representing higher seismic safety margin for SMRF buildings compared to IMRF system. The Calculated values of SFF for SMRF structures 



Fig. 10 IDA curves for IMRF and SMRF structures under near-field earthquakes

are slightly greater than those of IMRF system due to enhanced ductility. It is also conceived that the SSF values are smaller when the archetypes are under near-field earthquakes.

In order to determine the over-strength factor $\left(\Omega_{0}\right)$, the average of over-strength values $(\Omega)$ in the performance groups must be calculated. According to the FEMA P695 guidelines, the proposed over-strength factor $\left(\Omega_{0}\right)$ for a system should not be less than the maximum $\Omega$ value. On the other hand, according to Table 12.2-1 ASCE/SEI 7, the maximum over-strength value for the lateral load resisting systems is 3 , in this respect over-strength factor $\left(\Omega_{0}\right)$ should not be greater than 3 . In this study, the average of overstrength factors of IMRF structures was calculated 2.4. This value needs to be rounded to half unit intervals based on FEMA P695 methodology, thereby the proposed value of 2.5 is recommended for IMRF system. As well as this, in the same table, the average values of the over-strength factor $\left(\Omega_{0}\right)$ for SMRF structures is equal to 4.34. According to the above explanation, the proposed value for the special bending frame is 3, which is considered in the Standard No. 2800.

\section{Discussions and conclusions}

Previous researches focused on the estimation of R-factor reliability in the collapse prevention performance objective [2], while preferred performance objective for 

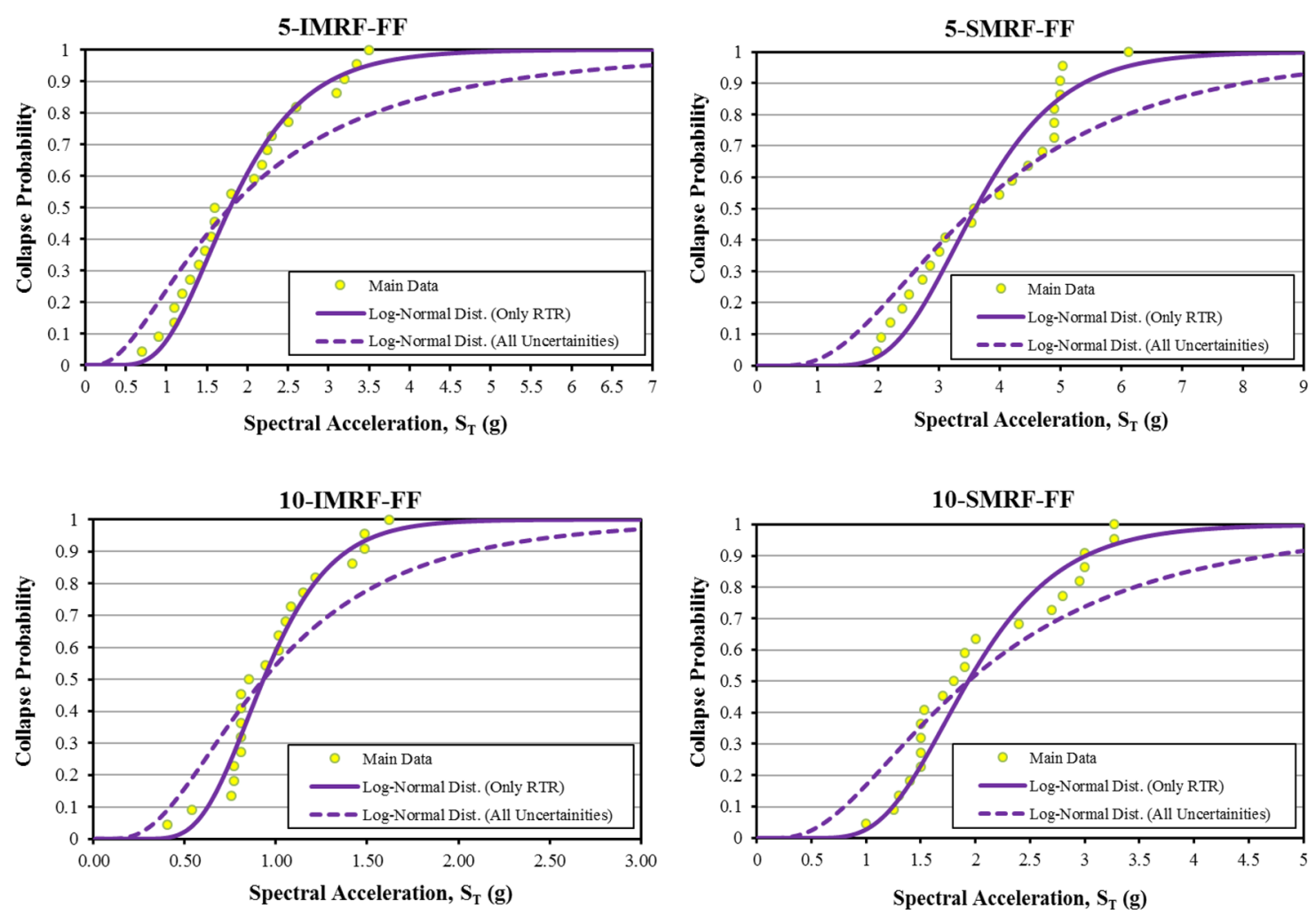

15-IMRF-FF


Fig. 11 Collapse fragility curves for archetypes subjected to far-field earthquakes

obtaining appropriate R-factor in current design code is life safety $[16,26,27]$. Furthermore, the effects of seismic sources to building sites were not investigated thoroughly and the number of applied ground motion records were limited [3]. Hence the validity of their results can be questionable and cause some inconsistencies between the results, hence it needs further attention $[4,41]$. However, findings of this study can be more trustworthy in terms of the number of applied ground motion records and more specifically the consideration of pulse-like and non-pulse-like ground motion record sets. In addition, the collapse probability of structures can be obtained easily from fragility curves presented in this study.
Herein it was observed that under almost half of nearfield records, ground motion records caused the low-rise archetype to collapse which is contradictory to the previous research [41] where these structures completely survived under the ground motion intensity at $3.0 \mathrm{~g}$. On the other hand, under far-field ground motion records it was reported that all the structures experienced collapse when the ground motion intensity reached $3.0 \mathrm{~g}$, while herein the probability of collapse for low-rise building was nearly $30 \%$ and for mid-to-high rise buildings they were around $90 \%$. In a study conducted by Abdollahzadeh, Sadeghi [42] on the seismic performance factors of 5-, 10, 15-story IMRFs using Young's method, the results indicated that on average the response modification factor around 5.5 



Fig. 12 Collapse fragility curves for archetypes subjected to near-field earthquakes

Table 7 The values of different uncertainties and total collapse uncertainty

\begin{tabular}{lllllll}
\hline Archetype ID & $\mu_{T}$ & $\beta_{\text {RTR }}$ & $\begin{array}{l}\beta_{\mathrm{DR}} \\
\text { Design qual- } \\
\text { ity=Superior }\end{array}$ & $\begin{array}{l}\beta_{\mathrm{TD}} \\
\text { Test data qual- } \\
\text { ity=Good }\end{array}$ & $\begin{array}{l}\beta_{\text {MDL }} \\
\text { Modelling qual- } \\
\text { ity=Good }\end{array}$ & $\beta_{\text {TOT }}$ \\
\hline 5-IMRF & 2.82 & 0.382 & 0.10 & 0.20 & 0.20 & 0.48 \\
10-IMRF & 3.85 & 0.4 & 0.10 & 0.20 & 0.20 & 0.50 \\
15-IMRF & 3.67 & 0.4 & 0.10 & 0.20 & 0.20 & 0.50 \\
5-SMRF & 4.35 & 0.4 & 0.10 & 0.20 & 0.20 & 0.50 \\
10-SMRF & 4.28 & 0.4 & 0.10 & 0.20 & 0.20 & 0.50 \\
15-SMRF & 3.32 & 0.4 & 0.10 & 0.20 & 0.20 & 0.50 \\
\hline
\end{tabular}


Table 8 Results of IDA under far-field and near-field records

\begin{tabular}{llll}
\hline ID & $\hat{S}_{C T}(g)$ & $\hat{S}_{M T}(g)$ & CMR \\
\hline PG-1 & & & \\
5-IMRF-FF & 1.80 & 1.05 & 1.71 \\
10-IMRF-FF & 0.95 & 0.68 & 1.41 \\
15-IMRF-FF & 0.7 & 0.54 & 1.30 \\
Average & 1.15 & - & 1.47 \\
PG-2 & & & \\
5-SMRF-FF & 3.6 & 1.05 & 3.44 \\
10-SMRF-FF & 1.93 & 0.68 & 2.86 \\
15-SMRF-FF & 1.77 & 0.54 & 3.27 \\
Average & 2.43 & - & 3.19 \\
PG-3 & & & \\
5-IMRF-NF & 1.64 & 1.05 & 1.56 \\
10-IMRF-NF & 0.76 & 0.68 & 1.12 \\
15-IMRF-NF & 0.53 & 0.54 & 0.98 \\
Average & 0.98 & - & 1.22 \\
PG-4 & & & \\
5-SMRF-NF & 2.89 & 1.05 & 2.76 \\
10-SMRF-NF & 1.53 & 0.68 & 2.27 \\
15-SMRF-NF & 1.35 & 0.54 & \\
Average & 1.92 & - & \\
\hline & & & \\
\hline
\end{tabular}

Table 9 Seismic parameters and collapse assessment of archetypes under far-field and near-field records can be acceptable, while in this study it is proofed that, the response modification factor of 5.0 is not acceptable for IMRF system subjected to near-field ground motion records using FEMA P695 methodology. On the other hand, for response modification factor of regular ductile structures a conservative value of 6.5 was proposed by Ferraioli et al. [43], while herein this value is increased to 7.5. According to the results of this study, SMRF designed with $R=7.5$ can also exhibit high levels of safety against collapse even for archetypes with high aspect ratio.

In addition to the above discussions, a comprehensive list of quantified advantages of SMRF system are presented in this study over IMRF system. According to pushover analyses results, the effective yield displacement $\left(\delta_{\mathrm{y}, \mathrm{eff}}\right)$, the average of period-based ductility factor $\left(\mu_{T}\right)$, overstrength factor $(\Omega)$ and the ultimate displacement $\left(\delta_{\mathrm{u}}\right)$ of SMRF system were greater than the corresponded values for intermediate moment resisting frame archetypes. Comparison of IDA curves showed that with the increase in the height, collapse of IMF and SMF buildings occurred at lower spectral accelerations under both far-field and nearfield records. In other words, in both lateral load resisting systems, as the height of structures increased the median collapse capacity $\left(\hat{S}_{C T}\right)$ and Collapse Margin Ratio (CMR) decreased. This is due to the fact that in high-rise buildings P-Delta effect causes instability of structures by exerting additional eccentric forces. IDA plots also revealed that in IMRF archetypes the carves became flatten in

\begin{tabular}{|c|c|c|c|c|c|c|c|}
\hline \multirow[t]{2}{*}{ Archetype } & \multicolumn{5}{|c|}{ Results } & \multicolumn{2}{|l|}{ Criteria } \\
\hline & $\Omega$ & $\mu_{T}$ & CMR & SSF & $A C M R_{i}$ & $\begin{array}{l}\text { Acceptable } \\
\text { Value }\end{array}$ & Pass/Fail \\
\hline \multicolumn{8}{|l|}{$P G-1$} \\
\hline 5-IMRF-FF & 2.50 & 2.82 & 1.71 & 1.20 & 2.06 & 1.52 & Pass \\
\hline 10-IMRF-FF & 2.83 & 3.85 & 1.41 & 1.32 & 1.87 & 1.52 & Pass \\
\hline 15-IMRF-FF & 1.89 & 3.67 & 1.30 & 1.38 & 1.80 & 1.52 & Pass \\
\hline Average & 2.40 & 3.45 & 1.47 & 1.29 & 1.92 & 1.90 & Pass \\
\hline \multicolumn{8}{|l|}{$P G-2$} \\
\hline 5-SMRF-FF & 4.31 & 4.35 & 3.44 & 1.25 & 4.30 & 1.52 & Pass \\
\hline 10-SMRF-FF & 4.61 & 4.28 & 2.86 & 1.33 & 3.80 & 1.52 & Pass \\
\hline 15-SMRF-FF & 4.11 & 3.32 & 3.27 & 1.34 & 4.38 & 1.52 & Pass \\
\hline Average & 4.34 & 3.98 & 3.19 & 1.31 & 4.16 & 1.90 & Pass \\
\hline \multicolumn{8}{|l|}{$P G-3$} \\
\hline 5-IMRF-NF & 2.50 & 2.82 & 1.56 & 1.13 & 1.76 & 1.52 & Pass \\
\hline 10-IMRF-NF & 2.83 & 3.85 & 1.12 & 1.20 & 1.34 & 1.52 & Fail \\
\hline 15-IMRF-FF & 1.89 & 3.67 & 0.98 & 1.29 & 1.26 & 1.52 & Fail \\
\hline Average & 2.40 & 3.45 & 1.22 & 1.20 & 1.47 & 1.90 & Fail \\
\hline \multicolumn{8}{|l|}{$P G-4$} \\
\hline 5-SMRF-NF & 4.31 & 4.35 & 2.76 & 1.17 & 3.23 & 1.52 & Pass \\
\hline 10-SMRF-NF & 4.61 & 4.28 & 2.27 & 1.24 & 2.81 & 1.52 & Pass \\
\hline 15-SMRF-NF & 4.11 & 3.32 & 2.50 & 1.27 & 3.17 & 1.52 & Pass \\
\hline Average & 4.34 & 3.98 & 2.51 & 1.23 & 3.07 & 1.90 & Pass \\
\hline
\end{tabular}


the Maximum inter-story drift range between 0.03 and 0.06 , however in SMRF archetypes the IDA curves demonstrated an upward trend toward the large inter-story drifts. In other words, SMRF archetypes have the potential to resist against extreme earthquakes and do not completely lose their robustness even in the large inter-story drifts. This was also evident in fragility curves where, the collapse probabilities of SMRFs were nearly zero under near-field and far-field ground motion records equivalent to maximum considered earthquake intensity $\left(\hat{S}_{M T}\right)$, in the range of $0.54-1.05(\mathrm{~g})$. However, the probability of collapse increased up to 30 and $50 \%$ for IMRFs under far-field and near-field records, respectively. This resulted in higher collapse margin ratios (CMR) and adjusted collapse margin ratios (ACMR) of SMRF structures than those of IMRF structures subjected to far-field or near-field earthquakes. Nonetheless, the probability of collapse increased significantly when both IMRF and SMRF systems subjected to near-field earthquakes compared to far-field earthquakes.

The response modification factors of 5.0 and 7.5 introduced in Iranian code of practice for seismic resistance design of buildings with IMRF and SMRF systems, are acceptable according to the requirements of FEMA P695, when they are located in the areas far away from potential faults. On the other hand, while under nearfield earthquakes the SMRF system satisfied FEMA P695 requirements, the IMRF structures designed with the response modification factor of 5.0 failed to meet these requirements. Therefore, it is not recommended to use this response factor for the design of the buildings with IMRF system located near the potential faults. All in all, according to the outcomes in this study, it is necessary to consider the superiority of SMRF system in constructions close to fault zones and incorporate this as a requirement in current design codes.

Herein, the over-strength factor of 3.0 and 2.5 are suggested for SMRF and IMRF systems, respectively. Nonetheless, since these suggested values are dependent to the variables which were considered in the design stage of archetypes, it is recommended for future studies to focus on different aspects of preliminary design assumptions e.g. occupancy, beam spans, number of bays, story heights and seismic design category to include a broad range of variables and gain a more suitable estimation of seismic performance factors.

This study has been carried out to evaluate the effects of near-field and far-field ground motions using FEMA P695 methodology on the buildings designed with the R-values proposed in Iranian code of practice. In addition, Effects of different uncertainties on the collapse capacity and fragility curves of structures including record-torecord $\left(\beta_{\text {RTR }}\right)$ uncertainty, design requirement $\left(\beta_{D R}\right)$ uncertainty, test data $\left(\beta_{\mathrm{TD}}\right)$ uncertainty, and modelling $\left(\beta_{\mathrm{MDL}}\right)$ uncertainty were investigated thoroughly. Analysis results are strictly valid for the range of parameters considered in this study. However, further studies for considering the effects of other parameters such as material variability are suggested for future research.

\section{Compliance with ethical standard}

Conflict of interest On behalf of all authors, the corresponding author states that there is no conflict of interest.

Open Access This article is licensed under a Creative Commons Attribution 4.0 International License, which permits use, sharing, adaptation, distribution and reproduction in any medium or format, as long as you give appropriate credit to the original author(s) and the source, provide a link to the Creative Commons licence, and indicate if changes were made. The images or other third party material in this article are included in the article's Creative Commons licence, unless indicated otherwise in a credit line to the material. If material is not included in the article's Creative Commons licence and your intended use is not permitted by statutory regulation or exceeds the permitted use, you will need to obtain permission directly from the copyright holder. To view a copy of this licence, visit http://creativecommons.org/licenses/by/4.0/.

\section{References}

1. Alavi B, Krawinkler $\mathrm{H}$ (2004) Behavior of moment-resisting frame structures subjected to near-fault ground motions. Earthq Eng Struct Dyn 33(6):687-706. https://doi.org/10.1002/eqe.369

2. Lee K, Foutch DA (2006) Seismic evaluation of steel moment frame buildings designed using different R-values. J Struct Eng 132(9):1461-1472. https://doi.org/10.1061/ (ASCE)0733-9445(2006)132:9(1461)

3. Asgarian B, Sadrinezhad A, Alanjari P (2010) Seismic performance evaluation of steel moment resisting frames through incremental dynamic analysis. J Constr Steel Res 66(2):178-190. https://doi.org/10.1016/j.jcsr.2009.09.001

4. Asgarian B, Khazaee H, Mirtaheri M (2012) Performance evaluation of different types of steel moment resisting frames subjected to strong ground motion through incremental dynamic analysis. Int J Steel Struct 12(3):363-379. https://doi. org/10.1007/s13296-012-3006-6

5. Izadinia M, Rahgozar MA, Mohammadrezaei O (2012) Response modification factor for steel moment-resisting frames by different pushover analysis methods. J Constr Steel Res 79:83-90. https://doi.org/10.1016/j.jcsr.2012.07.010

6. Kazantzi A, Vamvatsikos D, Lignos D (2014) Seismic performance of a steel moment-resisting frame subject to strength and ductility uncertainty. Eng Struct 78:69-77. https://doi.org/10.1016/j. engstruct.2014.06.044

7. Asgarian B, Ordoubadi B (2016) Effects of structural uncertainties on seismic performance of steel moment resisting frames. J Constr Steel Res 120:132-142. https://doi.org/10.1016/j. jcsr.2015.12.031

8. Noh HY, Lignos DG, Nair KK, Kiremidjian ASJEE, Dynamics $S$ (2012) Development of fragility functions as a damage classification/prediction method for steel moment-resisting frames using a wavelet-based damage sensitive feature. Earthq Eng Struct 41(4):681-696

9. Otsuki Y, Kurata M, Skalomenos KA, Ikeda YJEE, Dynamics $S$ (2019) Damage sequence and safety margin assessment of

\section{SN Applied Sciences}


expansion joints by shake table testing. Earthq Eng Struct Dyn 48(1):3-26

10. Macedo L, Silva A, Castro JJES (2019) A more rational selection of the behaviour factor for seismic design according to Eurocode 8. Eng Struct 188:69-86

11. Piluso V, Pisapia A, Castaldo P, Nastri E (2019) Probabilistic theory of plastic mechanism control for steel moment resisting frames. Struct Saf 76:95-107. https://doi.org/10.1016/j.strus afe.2018.08.003

12. Kiakojouri F, Sheidaii M, De Biagi V, Chiaia B (2020) Progressive collapse assessment of steel moment-resisting frames using static-and dynamic-incremental analyses. J Perform Constr Facil 34(3):04020025. https://doi.org/10.1061/(ASCE)CF.19435509.0001425

13. Nastri E, D'Aniello M, Zimbru M, Streppone S, Landolfo R, Montuori R, Piluso V (2019) Seismic response of steel Moment Resisting Frames equipped with friction beam-to-column joints. Soil Dyn Earthq Eng 119:144-157. https://doi.org/10.1016/j.soild yn.2019.01.009

14. Mahmoudi F, Dolatshahi KM, Mahsuli M, Nikoukalam MT, Shahmohammadi A (2019) Experimental study of steel moment resisting frames with shear link. J Constr Steel Res 154:197-208. https://doi.org/10.1016/j.jcsr.2018.11.027

15. Jamshidiha $H$, Yakhchalian $M(2019)$ New vector-valued intensity measure for predicting the collapse capacity of steel moment resisting frames with viscous dampers. Soil Dyn Earthq Eng 125:105625. https://doi.org/10.1016/j.soildyn.2019.03.039

16. FEMA P695 (2009) Quantification of building seismic performance factors. Federal Emergency Management Agency, Washington, DC

17. Zareian F, Lignos D, Krawinkler H (2010) Evaluation of seismic collapse performance of steel special moment resisting frames using FEMA P695 (ATC-63) methodology. In: Structures Congress 2010 pp 1275-1286. https://doi.org/10.1061/41130(369)116

18. Gade VP, Sahoo DR (2016) Evaluation of collapse-resistance of special truss moment frames as per FEMAp695 approach. Eng Struct 126:505-515. https://doi.org/10.1016/j.engst ruct.2016.08.015

19. Nobahar E, Farahi M, Mofid M (2016) Quantification of seismic performance factors of the buildings consisting of disposable knee bracing frames. J Constr Steel Res 124:132-141. https:// doi.org/10.1016/j.jcsr.2016.05.007

20. Asadi E, Adeli H (2018) Seismic performance factors for low-to mid-rise steel diagrid structural systems. Struct Des Tall Spec Build 27(15):e1505. https://doi.org/10.1002/tal.1505

21. Kheyroddin A, Mashhadiali N (2018) Response modification factor of concentrically braced frames with hexagonal pattern of braces. J Constr Steel Res 148:658-668. https://doi. org/10.1016/j.jcsr.2018.06.024

22. Özkılıç YO, Bozkurt MB, Topkaya C (2018) Evaluation of seismic response factors for BRBFs using FEMA P695 methodology. J Constr Steel Res 151:41-57. https://doi.org/10.1016/j. jcsr.2018.09.015

23. Heshmati M, Aghakouchak AA (2019) Quantification of seismic performance factors of steel diagrid system. Struct Des Tall Spec Build 28(3):e1572. https://doi.org/10.1002/tal.1572

24. Heshmati M, Khatami A, Shakib H (2020) Seismic performance assessment of tubular diagrid structures with varying angles in tall steel buildings. Structures 25:113-126. https://doi.org/10.1016/j. istruc.2020.02.030

25. Khatami A, Heshmati M, Aghakouchak AA (2020) Collapse assessment and seismic performance factors in tall tube-in-tube diagrid buildings. Earthq Struct 19(3):197-214. https://doi.org/10.12989/ eas.2020.19.3.197
26. Standard No. 2800 (2014) Iranian Code of Practice for Seismic Resistance Design of Buildings, 4th Edition, Building and Housing Research Center [In Persian]

27. ASCE/SEI 7-10 (2010) Minimum design loads for buildings and other structures. American Society of Civil Engineering, Reston

28. ANSI/AISC 360-10 (2010) Specification for structural steel buildings. American Institute of Steel Construction, Chicago

29. ANSI/AISC 341-10 (2010) Seismic provisions for structural steel buildings. American Institute of Steel Construction, Chicago

30. Skalomenos KA, Hatzigeorgiou GD, Beskos DEJEE, Dynamics S (2015) Modeling level selection for seismic analysis of concretefilled steel tube/moment-resisting frames by using fragility curves. Earthq Eng Struct Dyn 44(2):199-220

31. Mazzoni S, McKenna F, Scott MH, Fenves GL (2009) OpenSees Version 2.4.5 user manual. Pacific Earthquake Engineering Research Center (PEER), University of California, Berkeley

32. OpenSEES site Dynamic Analysis of 2-Story Moment Frame, Laura Eads, Stanford University. https://opensees.berkeley.edu/wiki/ index.php/Dynamic_Analysis_of_2-Story_Moment_Frame

33. (ATC-72-1) ATC (2010) Modeling and acceptance criteria for seismic design and analysis of tall buildings. Applied Technology Council Redwood City, Redwood City

34. ASCE (2013) Seismic evaluation and retrofit of existing buildings. American Society of Engineers, Reston

35. Krawinkler $\mathrm{H}$ (1978) Shear in beam-column joints in seismic design of steel frames. Eng J 15(3):82-91

36. Powel G (2011) User guide perform-3D version 5-nonlinear analysis and performance assessment for 3D structures. Computer and Structures Inc, California

37. FEMA (2009) Quantification of building seismic performance factors. FEMA P695. Federal Emergency Management Agency, Washington

38. Iervolino I, Manfredi G (2008) A review of ground motion record selection strategies for dynamic structural analysis. In: BursiWagg OSD (ed) Modern testing techniques for structural systems. Springer, Berlin, pp 131-163

39. Vamvatsikos D, Cornell CA (2002) Incremental dynamic analysis. Earthq Eng Struct Dyn 31(3):491-514

40. Kircher C, Deierlein G, Hooper J, Krawinkler H, Mahin S, Shing B, Wallace J (2010) Evaluation of the FEMA P-695 methodology for quantification of building seismic performance factors

41. Nazri FM, Ken PYJFoS, Engineering C, (2014) Seismic performance of moment resisting steel frame subjected to earthquake excitations. Front Struct Civ Eng 8(1):19-25. https://doi.org/10.1007/ s11709-014-0240-3

42. AbdollahzadehSadeghi GA (2018) Earthquake recurrence effect on the response reduction factor of steel moment frame. Asian J Civ Eng 19(8):993-1008. https://doi.org/10.1007/s42107-018-0079-3

43. FerraioliLavinoMandara MAA (2014) Behaviour factor of codedesigned steel moment-resisting frames. Int J Steel Struct 14(2):243-254. https://doi.org/10.1007/s13296-014-2005-1

Publisher's Note Springer Nature remains neutral with regard to jurisdictional claims in published maps and institutional affiliations. 